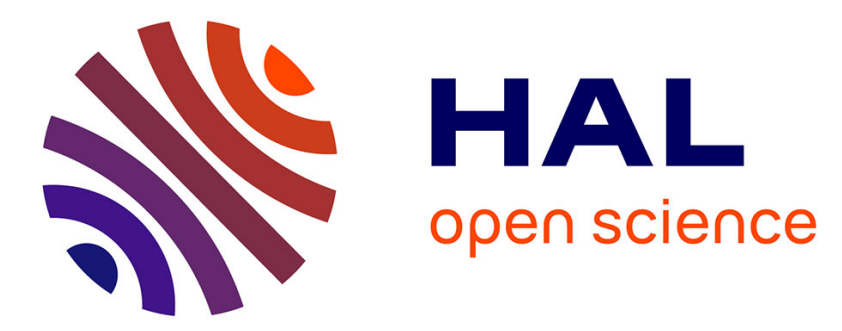

\title{
Spin-dependent scattering lengths of slow neutrons with nuclei by pseudomagnetic measurements
}

\author{
A. Abragam, G.L. Bacchella, H. Glättli, P. Meriel, J. Piesvaux, M. Pinot
}

\section{To cite this version:}

A. Abragam, G.L. Bacchella, H. Glättli, P. Meriel, J. Piesvaux, et al.. Spin-dependent scattering lengths of slow neutrons with nuclei by pseudomagnetic measurements. Journal de Physique Lettres, 1975, 36 (11), pp.263-265. 10.1051/jphyslet:019750036011026300 . jpa-00231204

\section{HAL Id: jpa-00231204 https://hal.science/jpa-00231204}

Submitted on 1 Jan 1975

HAL is a multi-disciplinary open access archive for the deposit and dissemination of scientific research documents, whether they are published or not. The documents may come from teaching and research institutions in France or abroad, or from public or private research centers.
L'archive ouverte pluridisciplinaire HAL, est destinée au dépôt et à la diffusion de documents scientifiques de niveau recherche, publiés ou non, émanant des établissements d'enseignement et de recherche français ou étrangers, des laboratoires publics ou privés. 


\title{
SPIN-DEPENDENT SCATTERING LENGTHS OF SLOW NEUTRONS WITH NUCLEI BY PSEUDOMAGNETIC MEASUREMENTS
}

\author{
A. ABRAGAM, G. L. BACCHELLA, H. GLÄTTLI, P. MERIEL, \\ J. PIESVAUX and M. PINOT \\ Service de Physique du Solide et de Résonance Magnétique, \\ Centre d'Etudes Nucléaires de Saclay, \\ B.P. n $^{\circ}$ 2, 91190 Gif-sur-Yvette, France
}

(Reçu le 16 juillet 1975, accepté le 4 septembre 1975)

\begin{abstract}
Résumé. - En mesurant la précession de spin de neutrons en fonction de la polarisation nucléaire, on a obtenu les valeurs de la longueur de diffusion dépendant du spin nucléaire pour les noyaux de ${ }^{23} \mathrm{Na},{ }^{59} \mathrm{Co},{ }^{63} \mathrm{Cu},{ }^{65} \mathrm{Cu},{ }^{195} \mathrm{Pt},{ }^{197} \mathrm{Au}$ et ${ }^{207} \mathrm{~Pb}$, ainsi qu'une valeur moyenne pour les deux isotopes du thallium et de l'argent dans l'élément naturel. On donne également une valeur corrigée pour ${ }^{91} \mathrm{Zr}$. La méthode a été étendue aux matériaux magnétiques. En utilisant du cobalt c.f.c. et hexagonal, on montre que les mesures pseudomagnétiques peuvent fournir des informations précises sur le champ interne $v u$ par les noyaux.
\end{abstract}

\begin{abstract}
The spin-dependent scattering length of slow neutrons by the nuclei ${ }^{23} \mathrm{Na},{ }^{59} \mathrm{Co}$, ${ }^{63} \mathrm{Cu},{ }^{65} \mathrm{Cu},{ }^{195} \mathrm{Pt},{ }^{197} \mathrm{Au}$ and ${ }^{207} \mathrm{~Pb}$, as well as the mean value for the two isotopes of $\mathrm{Tl}$ and $\mathrm{Ag}$ in the natural element have been obtained by measuring the precession of the neutron spins as a function of nuclear polarization. A revised value for ${ }^{91} \mathrm{Zr}$ is also given. The method has been extended for use with magnetic materials. Using f.c.c. and hexagonal cobalt, it is shown that these pseudomagnetic measurements may give precise information on the internal field seen by the nuclei.
\end{abstract}

The scattering of thermal neutrons by nuclei contains a spin-dependent part. In the present state of nuclear theory, in general this spin-dependent part does not seem to be accessible to model calculations. However, its value can be of practical importance in many thermal neutron scattering experiments.

A new method, called pseudomagnetic, has been described previously [1] and its usefulness for systematic measurements of spin-dependent scattering lengths $a_{\mathrm{N}}$ has been demonstrated [2]. In the present paper, values of $a_{\mathrm{N}}$ for seven more nuclei are reported and the problems connected with the extension of the method to magnetic materials are discussed.

In analogy to magnetic scattering, the influence of the nuclear spin-dependent scattering on a polarized neutron beam inside a polarized target can be described by a pseudomagnetic field $H^{*}=4 \pi M^{*}$ set up by the pseudomagnetic moments $\mu^{*}$ characteristic of the nuclei, such that $M^{*}=N \mu^{*} P$, where $N$ is the number of nuclei per unit volume and $P$ is the nuclear polarization. The neutron spins precess around this pseudomagnetic field and the resulting precession angle $\alpha_{\mathrm{N}}=\gamma_{\mathrm{n}} H^{*}(\mathfrak{L} / v)$ is measured. $\mathfrak{L}$ is the sample length, $v$ the neutron velocity and $\gamma_{\mathrm{n}}=2 \mu_{\mathrm{n}} / \hbar$ is the gyromagnetic ratio of the neutron. The pseudomagnetic moment is defined by :

where

$$
\mu^{*}=-\left(\mu_{\mathrm{B}} I / g_{\mathrm{n}} r_{0}\right) a_{\mathrm{N}}
$$

$$
a_{\mathrm{N}}=\left(a_{+}-a_{-}\right) /\left(I+\frac{1}{2}\right)
$$

is the familiar spin-dependent scattering length, $\mu_{\mathrm{B}}$ the Bohr magneton, $r_{0}$ the classical radius of the electron, and $g_{\mathrm{n}}=-1.913$ the measure in nuclear magnetons of the magnetic moment $\mu_{\mathrm{n}}$ of the neutron. The nuclear polarization is obtained by brute force in a field of $25 \mathrm{kOe}$ and at temperatures down to $T=30 \mathrm{mK}$. With such experimental conditions, the nuclear polarization in non-magnetic substances is given by the Curie law : $P=C / T$, and a plot of the precession angle $\alpha_{\mathrm{N}}$ versus $1 / T$ gives a straight line with a slope proportional to $\mu^{*}$. The results obtained in this way are given in table I.

If there are different nuclei with non-zero spin inside the target, a mean value

$$
\left\langle\frac{\mu^{*}}{\mu_{\mathrm{B}}}\right\rangle=\frac{\Sigma_{i} c_{i} P_{i} \frac{\mu_{i}^{*}}{\mu_{\mathrm{B}}}}{\Sigma_{i} c_{i} P_{i}}
$$


TABLE I

Values given in this table are corrected for thermal contraction at low temperatures whenever possible $(\mathrm{Co}, \mathrm{Zr}$ and $\mathrm{T} 1$ excepted). The $\mu^{*} / \mu_{\mathrm{B}}$ values given in column 4 between brackets (for natural $\mathrm{Cu}, \mathrm{T} 1$ and $\mathrm{Ag}$ ) are mean values (see text).

\begin{tabular}{|c|c|c|c|c|c|}
\hline Nucleus & Spin & $\begin{array}{c}\alpha_{\mathrm{N}} T / \mathbf{l} \\
\left(\operatorname{deg} . \mathrm{cm}^{-1} \cdot \mathrm{K}\right)\end{array}$ & $\mu^{*} / \mu_{\mathrm{B}}$ & $\begin{array}{c}a_{+}-a_{-} \\
\left(10^{-12} \mathrm{~cm}\right)\end{array}$ & $\underset{(\mathrm{mm})}{\mathrm{l}}$ \\
\hline- & - & - & - & - & - \\
\hline${ }^{23} \mathrm{Na}$ & $\frac{3}{2}$ & +9.64 & $+0.99 \pm 0.04$ & $+0.71 \pm 0.03$ & 23.0 \\
\hline${ }^{59} \mathrm{Co}$ (hex) & $\frac{7}{2}$ & & $-1.88 \pm 0.10$ & $-1.16 \pm 0.06$ & 0.9 \\
\hline${ }^{59} \mathrm{Co}$ (cub) & $\frac{7}{2}$ & & $-2.08 \pm 0.04$ & $-1.28 \pm 0.03$ & $\begin{array}{l}1.0 \\
2.35\end{array}$ \\
\hline${ }^{63} \mathrm{Cu}$ & $\frac{3}{2}$ & +1.97 & $+0.063 \pm 0.006$ & $+0.045 \pm 0.005$ & 13.6 \\
\hline $\mathrm{Cu}$ & & +6.75 & $\langle+0.207 \pm 0.011\rangle$ & & 25.85 \\
\hline${ }^{65} \mathrm{Cu}$ & $\frac{3}{2}$ & & $+0.51 \pm 0.02$ & $+0.37 \pm 0.02$ & \\
\hline${ }^{91} \mathrm{Zr}$ & $\frac{5}{2}$ & & $+0.34 \pm 0.05$ & $+0.22 \pm 0.03$ & 25.85 \\
\hline $\mathrm{Pt}$ & & -0.85 & & & 10.9 \\
\hline${ }^{195} \mathrm{Pt}$ & $\frac{1}{2}$ & & $-0.21 \pm 0.04$ & $-0.23 \pm 0.04$ & \\
\hline${ }^{197} \mathrm{Au}$ & $\frac{3}{2}$ & -0.71 & $-0.49 \pm 0.04$ & $-0.36 \pm 0.03$ & 6.0 \\
\hline $\mathrm{Tl}$ & & +0.52 & $\langle+0.030 \pm 0.006\rangle$ & & 23.0 \\
\hline $\mathrm{Ag}$ & & -0.16 & $\langle+0.073 \pm 0.015\rangle$ & & 10.6 \\
\hline $\begin{array}{r}\mathrm{Pb} \\
{ }_{207} \mathrm{~Pb}\end{array}$ & $\frac{1}{x}$ & +0.03 & $+002+0.04$ & $+002+0.04$ & 25.85 \\
\hline
\end{tabular}

is measured, where $c_{i}$ is the abundance of nucleus $i$. Such a mean value has been obtained for the elements $\mathrm{Ag}, \mathrm{Tl}$ and $\mathrm{Cu}$ with their natural abundance of isotopes. The contribution of ${ }^{63} \mathrm{Cu}$ has been measured separately on a $99.9 \%$ isotopically enriched sample. The pseudomagnetic moment of ${ }^{65} \mathrm{Cu}$ has been obtained by subtracting the contribution of ${ }^{63} \mathrm{Cu}$ from the mean value.

For ${ }^{207} \mathrm{~Pb}$, only an upper limit could be obtained. The fact that $\mathrm{Pb}$ did not give any detectable precession angle turned out to be very useful in the cases where the sample was too absorbing for neutrons (e.g. Au) or when it was not available in large amounts (e.g. ${ }^{63} \mathrm{Cu}$ ). In these cases, lead was a convenient neutral substance to keep ${ }^{3} \mathrm{He}$ out of the neutron path, by filling the empty space along this path in the dilution chamber.

The value of the pseudomagnetic moment of ${ }^{91} \mathrm{Zr}$ published in [2] is erroneous, since an analysis of the sample subsequent to publication has shown an amount of $27 \pm 3$ ppm (by weight) of hydrogen. Later on, the experiment has been repeated on a sample degassed in vacuum and which had only $8.6 \pm 1.0 \mathrm{ppm}$ of $\mathrm{H}$. Knowing the pseudomagnetic moment of ${ }^{1} \mathrm{H}\left(5.4 \mu_{\mathrm{B}}\right)$, it is possible to subtract the hydrogen contribution in both experiments. The result for ${ }^{91} \mathrm{Zr}$ given in table $\mathrm{I}$ is the weighted mean of the two measurements corrected in this way.

The measurement of nuclear pseudomagnetic moments in ferromagnetic materials raises two new problems connected respectively with the large electronic magnetization and the existence, within the sample, of a strong internal field seen by the nuclei.
At low temperatures, where the nuclear neutron precession becomes appreciable, the large electronic magnetization does not prevent a determination of the nuclear polarization. Although the contribution $\alpha_{\mathrm{e}}$ to the neutron precession angle, resulting from the high electron induction inside the sample $B_{\mathrm{e}}=4 \pi M_{\mathrm{e}}$ $\left(\alpha_{\mathrm{e}}=\gamma_{\mathrm{n}} 4 \pi M_{\mathrm{e}}(\mathcal{L} / v)\right)$ is very much larger than the nuclear precession angle $\alpha_{N}=\gamma_{n} 4 \pi N \mu^{*} P(\mathcal{L} / v)$, one is tempted to argue that, as long as the rate of change with temperature $\left|\mathrm{d} \alpha_{\mathrm{e}} / \mathrm{d} T\right|$ is much smaller than $\left|\mathrm{d} \alpha_{\mathrm{N}} / \mathrm{d} T\right|$, the effects of the strong electronic induction inside the sample can be disregarded.

This would be true if the neutron beam were strictly monoenergetic. However, in the presence of a velocity spread $\delta v$, the precessing neutron spins will fan out in the plane perpendicular to the magnetization through an angle $\left|\delta \alpha_{\mathrm{e}}\right|=\alpha_{\mathrm{e}}|\delta v / v|$, and their precessing vector polarization will be decreased. For example, assuming a gaussian velocity distribution of halfwidth $\Delta v$, the neutron polarization is reduced in the ratio

$$
\rho=\exp \left[-\left(\alpha_{\mathrm{e}}^{2} / 2\right)(\Delta v / v)^{2}\right]
$$

For $v=4 \times 10^{5} \mathrm{~cm} / \mathrm{s}, \Delta v / v=1.5 \%$ and $M_{\mathrm{e}}=1.4 \mathrm{kG}$, one finds that

$$
\rho \simeq \exp \left(-33 \mathfrak{L}^{2}\right) \simeq 0.05 \text { for } \mathcal{L}=3 \mathrm{~mm} .
$$

Actually, the limitation on the admissible thickness of the sample, and therefore on the magnitude of the nuclear precession angle $\alpha_{N}$, is less severe. The lines of force of the electronic induction continue outside the sample. The effect of the electronic induction 
outside the sample on the neutron spin precession is opposite to that inside the sample. By choosing a suitable geometry of the target, the total precession angle due to the electronic magnetization can be made small. For instance, for a narrow beam arriving at the center of a rectangular target of sides $a_{\|}$and $a_{\perp}$ (to the field), it is found that the value of $\alpha_{\mathrm{e}}$ is reduced in the ratio

$$
\eta=1-\frac{2}{\pi} \tan ^{-1}\left(a_{\perp} / a_{\|}\right)
$$

which may be small if $a_{\perp} \gg a_{\|}$[7].

The second problem is the determination of the nuclear polarization inside the sample, which requires the knowledge of the internal field $H_{\mathrm{i}}$ seen by the nuclei. This field is usually far larger than the applied field $H_{0}$ (a favourable circumstance). It can be broken into two parts : $H_{\mathrm{i}}=H_{\mathrm{hfs}}+H_{\mathrm{d}}$. $H_{\mathrm{hfs}}$ is the sum of the fields produced at the nucleus by the electrons ( $d$ or $f$ ) of the magnetic ion to which the nucleus belongs and by the conduction electrons (if the sample is metallic). $H_{\mathrm{d}}$ is the dipolar field produced at the nucleus by all the other ions of the sample. Whereas $H_{\mathrm{hfs}}$ is independent of the shape of the sample and of the applied magnetic field [3], $H_{\mathrm{d}}$ is not. There are two types of experiments from which the values of $H_{\mathrm{i}}=H_{\mathrm{hfs}}+H_{\mathrm{d}}$ can be extracted : specific heat measurements and N.M.R. It turns out that for most materials $H_{\mathrm{d}}$ is only a few percent of $H_{\mathrm{hfs}}$ and within this accuracy, the values of $H_{\mathrm{i}}$ can be taken from any specific heat or resonance measurement. But if far greater accuracy is required, then the value of $H_{\mathrm{d}}$ will be appropriate to calculate $\mu^{*}$ only if the shape of the sample and the magnitude of the applied field in either type of experiment are the same as in the pseudomagnetic experiment. Results of measurements of specific heat or N.M.R. in zero applied field are difficult to interpret because the ferromagnetic sample breaks into domains whose shape has an influence on the value of $H_{\mathrm{d}}$. For N.M.R. experiments, a further complication arises from the fact that the measured N.M.R. frequency is that of nuclei in domain walls rather than in the bulk.

We have measured the neutron precession angle as a function of temperature for single crystals of both hexagonal and cubic cobalt.

For hexagonal cobalt, a precise specific heat measurement on a spherical single crystal in a high magnetic field gave $H_{\mathrm{i}}=223 \pm 1.5 \mathrm{kOe}$ [3]. Our measurements have been made on a disc of $3 \mathrm{~mm}$ diameter and $0.9 \pm 0.02 \mathrm{~mm}$ thickness, the [001] direction being parallel to the applied field $H_{0}$. Taking into account $H_{0}$ and the difference in demagnetizing factors between sphere and disc, the effective field for polarizing the Co nuclei can be estimated to $201 \pm 3 \mathrm{kOe}$. The corresponding value for $\mu^{*}$ is given in table I. Here, the accuracy of our measurement is not limited by the knowledge of $H_{\mathrm{i}}$.

The situation is different for cubic Co. Our measurements were done on 2 single crystals of $\mathrm{Co}_{0.92} \mathrm{Fe}_{0.08}$, a disc similar to the hexagonal sample, and a parallelepiped $16 \times 7 \times 2.35 \mathrm{~mm}$. The mean value of $\mu^{*}$, using the specific heat value $H_{\mathrm{i}}=220 \pm 4 \mathrm{kOe}[4]$ is shown in table I. Here, the dominant uncertainty is due to $H_{\mathrm{i}}$. This shows that pseudomagnetic measurements could be used to obtain reliable information about internal fields in magnetic samples. The values obtained compare well with the value $2.06 \pm 0.02$ obtained from scattering cross-section measurements [5], but are somewhat lower than that obtained by Bragg scattering of polarized neutrons on a polarized single crystal of cobalt [6] $\left(2.3 \pm 0.2\right.$ using the same $H_{\mathrm{hfs}}$ as for our results).

\section{References}

[1] Abragam, A., Bacchella, G. L., Glättli, H., Meriel, P., Pinot, M., Piesvaux, J., Phys. Rev. Lett. 31 (1973) 776.

[2] Roubeau, P., Abragam, A., Bacchella, G. L., Glättli, H., Malinovski, A., Meriel, P., Piesvaux, J., Pinot, M. Phys. Rev. Lett. 33 (1974) 102.

[3] Lanchester, P. C., Whitehead, N. F., Wells, P., Scurlock, R. G., J. Phys. F 5 (1975) 247.
[4] Arp, V., Edmonds, D., Petersen, R., Phys. Rev. Lett. 3 (1959) 212.

[5] Koester, L., Knopf, K., WaschKowski, W., Z. Phys. 271 (1974) 201.

[6] Ito, Y., Shull, C. G., Phys. Rev. 185 (1969) 961.

[7] We are indebted to Dr. M. Goldman who suggested to us this particular sample shape and who did the calculations of $\alpha_{\mathrm{e}}$. 